\title{
Enterobacter agglomerans: a new cause of primary pneumonia
}

\author{
$\sqrt{1}$
}

\section{S AL-DAMLUJI, CM DICKINSON, A BECK}

\section{From St Charles Hospital, London}

Enterobacteragglomerans(formerly known as Erwinia herbicola lathyri) is a Gram-negative bacillus belonging to the tribe Klebsielleae of the family Enterobacteriaceae. Members of the genus Enterobacterare distinguished from those of Klebsiella by their motility and inability to split urea. The organism is a plant pathogen ${ }^{1}$ and was considered unimportant clinically until the mid-1960s, when it was identified in hospital-acquired infections in debilitated patients (especially those receiving broad-spectrum antibiotics) as causing postoperative wound infections and urinary tract infections after instrumentation. ${ }^{2}$ Attention was focused on the organism in the early 1970 s in the United States, when it was implicated in an epidemic of septicaemia caused by contamination of bottle caps of intravenous fluid containers. ${ }^{3}$ Infections acquired outside hospital have usually been associated with contaminated agricultural wounds. ${ }^{4}$ The organism is generally regarded as opportunistic, of low virulence, and with little intrinsic invasiveness. We describe a patient with a fulminating primary pneumonia acquired outside hospital that was caused by Enterobacter agglomerans.

\section{Case report}

The patient was a 58-year-old man who smoked 20 cigarettes a day and had a 10-year history of chronic bronchitis (daily cough and sputum production with winter exacerbations). His symptoms, however, were mild in that he had required only one hospital admission with an acute exacerbation of chronic bronchitis 10 years previously and had worked full-time as a carpenter, with full exercise tolerance and no dyspnoea. His alcohol intake was heavy and he had had diabetes for 10 years but this was well controlled by diet alone. He presented to hospital with a three-day history of cough, haemoptysis, right pleuritic chest pain, and dyspnoea. Members of his family confirmed that there was no history of drinking bouts, unconsciousness or contact with ill people.

On examination he was very ill, dyspnoeic, and hypotensive, but was afebrile. He was jaundiced with slight hepatomegaly, but there were no physical signs of chronicliver disease. Venous pressure was not raised and there was nooedema. Heart sounds were normal. He had the physical signs of consolidation in the right lung and a chest radiograph confirmed consolidation in the right middle and lower lobes (fig).

Arterial blood gas sampling showed him to be hypoxic with a good ventilatory drive $\left(\mathrm{Po}_{2} 6.5 \mathrm{kPa}(49 \mathrm{~mm} \mathrm{Hg}), \mathrm{Pco}_{2} 2.53 \mathrm{kPa}\right.$ (19 $\mathrm{mm} \mathrm{Hg}), \mathrm{pH} \mathrm{7.43,} \mathrm{total} \mathrm{bicarbonate} 12 \mathrm{mmol}(\mathrm{mEq}) / 1$, and base excess $-8 \mathrm{mmol}(\mathrm{mEq}) / \mathrm{l})$; so he was treated with $40 \%$

Address for reprint requests: Dr S Al-Damluji, St Mary's Hospital, London W2 $1 \mathrm{NY}$.

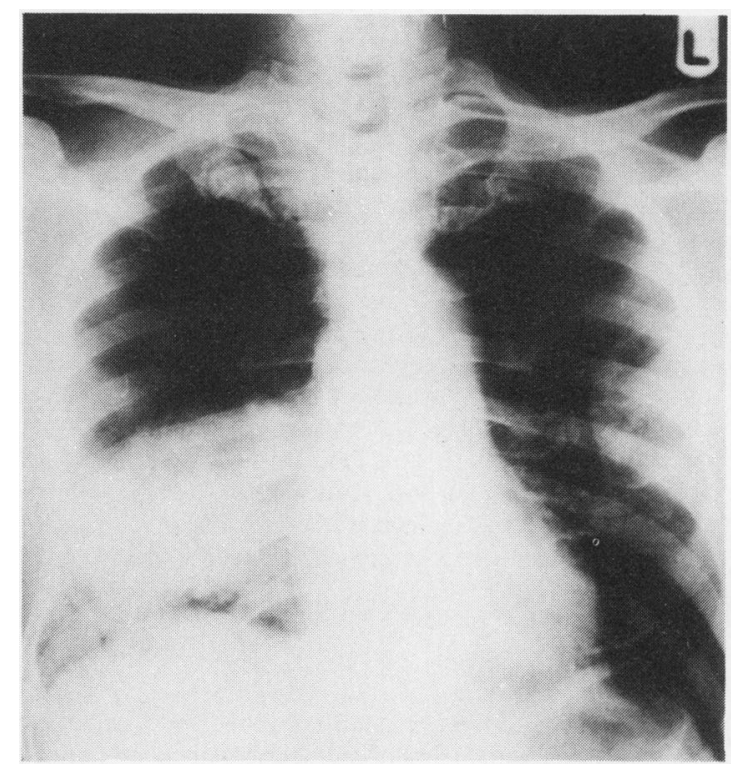

Chest radiograph showing consolidation in the right middle and lower lobes.

oxygen by face mask. The right atrial pressure was $9 \mathrm{~cm}$ saline. A diagnosis of septicaemia due to lobarpneumonia was madeand he was given ampicillin and gentamicin intravenously.

Shortly after admission the patient had a respiratory arrest. He was intubated immediately and ventilated mechanically but he remained hypoxaemic despite high inhaled oxygen concentrations, and hypotension persisted despite maintenance of an adequate venous pressure with colloid and administration of inotropic drugs. Ten hours after admission he developed cardiac asystole and died.

Investigations On admission the haemoglobin concentration was $16.1 \mathrm{~g} / \mathrm{dl}$, the WBC was $1.4 \times 109 / 1$ (60\%lymphocytes, $13 \%$ monocytes, $27 \%$ neutrophils) and the platelet count $35000 \times$ $109 / 1$. The prothrombin time was 25 seconds (control $12 \mathrm{~s}$ ) and the kaolin partial thromboplastin time was $116 \mathrm{~s}$ (control $47 \mathrm{~s}$ ). The blood urea concentration was $12.7 \mathrm{mmol} / 1(76.5 \mathrm{mg} / 100$ $\mathrm{ml})$; the electrolytes were normal; and the blood glucose concentration was $6.6 \mathrm{mmol} / 1(119 \mathrm{mg} / 100 \mathrm{ml})$.

Bacteriology Three consecutive blood cultures, a sputum specimen, and a postmortem lung specimen yielded pure cultures of a motile Gram-negative bacillus, which gave the following reactions in the API 20E series of tests: ONPG +; 
arginine dehydrolase -; lysine decarboxylase -; ornithine decarboxylase -; citrate $+; \mathrm{H}_{2} \mathrm{~S}-$; urea -; tryptophane desaminase-;indole-; VP+;gelatine-;glucose +; mannitol +; inositol - ; sorbitol + ; rhamnose + ; sucrose - ; melibiose + ; amygdaline + ; arabinose + ; oxidase -. These reactions identified the organism as Enterobacter agglomerans. The organism was sensitive to gentamicin, trimethoprim, colistin, and cephaloridine and resistant toampicillin, ticarcillin, sulphafurazole, and tetracycline.

Necropsy There was bilateral fibrinous pleurisy and the trachea and main bronchi contained brown, purulent material. The right middle and lower lobes were extensively consolidated, there were areas of haemorrhage, and the texture of the lung substance resembled necroticliver. There were early similar changes in the left lower lobe. Histological examination showed an acute necrotising bronchopneumonia with haemorrhagic areas and many Gram-negative organisms were visible. The pericardium showed mild inflammatory changes and the pericardial sac contained a little cloudy fluid, but the cardiovascular system was otherwise normal. The liver (weight $2030 \mathrm{~g}$ ) had a normal external appearance but histological examination showed an excess of fibrous tissue in the portal tracts and the hepatocytes showed moderate large-vacuole fat with no Mallory's hyaline. There was some acute centrilobular necrosis and cholestasis and the overall appearances were thought to be consistent with septicaemia. The bone marrow appeared normal on histological examination, and the nakedeye and microscopic appearances of the other organs were also normal.

\section{Discussion}

Enterobacter agglomerans has only rarely been implicated with confidence as a human pathogen; when found in sputum it is usually in combination with known pathogens and is presumed to be a commensal or a contaminant. ${ }^{45}$ There is no doubt of the pathogenicity of the organism in this case as it was isolated in pure growth from blood, sputum, and postmortem lung specimens. Enterobacter agglomerans has been implicated in indolent lung 6 and brain ${ }^{7}$ abscesses but there are apparently no reports of a primary pneumonia caused by this organism. The incidence of bacteraemia due to Enterobacter agglomerans is low, a total of 38 cases having been reported to the Communicable Disease Surveillance Centre in the five years 1975-9 (unpublished report 30 May 1980). This represented 7\% of all bacteraemias due to members of the genus Enterobacter reported in this period.

We can only speculate on the factors that predisposed the patient to this illness as we were unable in the time available to investigate his immune function. His normal bone marrow indicates that the neutropenia and thrombocytopenia were due to increased peripheral consumption secondary to septicaemia. The history of chronic bronchitis, alcoholism, and diabetes may be relevant, as may variations in the virulence of the organism.

We thank Dr MJ Kershaw for the postmortem examination, Mrs SB Kent for typing the manuscript, and Dr M Harington for permission to report the case.

\section{References}

'Starr MP, Chatterjee AK. The genus Erwinia: enterobacteria pathogenic to plants and animals. Ann Rev Microbiol 1972;26:389-426.

2 Steinhauer BW, Eickhoff TC, Kislak JW, et al. The Klebsiella-Enterobacter-Serratia division: clinical and epidemiological characteristics. Ann Intern Med 1966;65:1180-94.

${ }^{3}$ Maki DG, Rhame FS, Mackel DC, Bennett JO. Nationwide epidemic of septicaemia caused by contaminated intravenous products. Am JMed 1976;60:471-85.

${ }^{4}$ Pien FD, Martin WJ, Hermans PE, et al. Clinical and bacteriologic observations on the proposed species Enterobacter agglomerans (the herbicola-lathyri bacteria). Mayo Clin Proc 1972;47:739-45.

${ }^{5}$ Geere IW. Enterobacter agglomerans: the clinically important plant pathogen. Can Med AssocJ 1977;116:5179.

${ }^{6}$ Reed WP. Indolent pulmonary abscess associated with Klebsiella and Enterobacter. Am Rev Respir Dis 1973;107:1055-9.

7 Wechsler A, Bottone E, Lasser R, Koverman G. Brain abscess caused by an Enwinia species. Am $J$ Med 1971;51:680-4. 